\title{
Article \\ Chitosan Enhances the Anti-Biofilm Activity of Biodentine against an Interkingdom Biofilm Model
}

\author{
Sumaya Abusrewil ${ }^{1}$, Jason L. Brown ${ }^{2}{ }^{(D}$, Christopher Delaney ${ }^{2}$, Mark C. Butcher ${ }^{2}$, Mohammed Tiba ${ }^{1}{ }^{(\mathbb{D},}$ \\ J. Alun Scott ${ }^{1}$, Gordon Ramage ${ }^{1,2} \mathbb{1}$ and William McLean ${ }^{1, *}$ \\ 1 Glasgow Endodontology Group, Glasgow Dental School, School of Medicine, Dentistry and Nursing, \\ College of Medical, Veterinary and Life Sciences, Glasgow G12 8QF, UK; 2224354A@student.gla.ac.uk (S.A.); \\ 2538282T@student.gla.ac.uk (M.T.); james.scott@glasgow.ac.uk (J.A.S.); gordon.ramage@glasgow.ac.uk (G.R.) \\ 2 Oral Sciences Research Group, Glasgow Dental School, School of Medicine, Dentistry and Nursing, \\ College of Medical, Veterinary and Life Sciences, University of Glasgow, 378 Sauchiehall Street, \\ Glasgow G2 3JZ, UK; Jason.brown@glasgow.ac.uk (J.L.B.); Christopher.delaney@glasgow.ac.uk (C.D.); \\ 2135158B@student.gla.ac.uk (M.C.B.) \\ * Correspondence: william.mclean@glasgow.ac.uk; Tel.: +44(0)141-956-0991
}

check for updates

Citation: Abusrewil, S.; Brown, J.L.; Delaney, C.; Butcher, M.C.; Tiba, M.; Scott, J.A.; Ramage, G.; McLean, W. Chitosan Enhances the Anti-Biofilm Activity of Biodentine against an Interkingdom Biofilm Model. Antibiotics 2021, 10, 1317. https:// doi.org/10.3390/antibiotics10111317

Academic Editors: Susana Patrícia Lopes and Diana Alves

Received: 2 October 2021

Accepted: 26 October 2021

Published: 29 October 2021

Publisher's Note: MDPI stays neutral with regard to jurisdictional claims in published maps and institutional affiliations.

Copyright: (C) 2021 by the authors Licensee MDPI, Basel, Switzerland. This article is an open access article distributed under the terms and conditions of the Creative Commons Attribution (CC BY) license (https:/ / creativecommons.org/licenses/by/ $4.0 /)$.

\begin{abstract}
Endodontic infection is a biofilm disease that is difficult to irradicate with current treatment protocols, and as such, persistent micro-organisms may lead to ongoing or recurrent disease. The potential for the use of enhanced filling materials to modify biofilm regrowth is a promising strategy. This current study aimed to evaluate the anti-biofilm efficacy of calcium silicate cements modified with chitosan. The development of mono-species and multi-species biofilms on ProRoot MTA, Biodentine and bovine dentine discs were explored using quantitative microbiology analysis. The effect on regrowth of biofilms was assessed following the addition of chitosan to each cement. In comparison to a dentine substrate, both materials did not show the ability to inhibit biofilm regrowth. Biodentine incorporated with chitosan displayed a dose-dependent reduction in multispecies biofilm regrowth, unlike MTA. Notably, interkingdom biofilms were shown to enhance bacterial tolerance in the presence of chitosan. This study demonstrates the potential to enhance the antimicrobial properties of Biodentine. The findings highlight the need for appropriate model systems when exploring antimicrobial properties of materials in vitro so that interspecies and interkingdom interactions that modify tolerance are not overlooked while still supporting the development of innovative materials.
\end{abstract}

Keywords: endodontics; bioceramics; chitosan; biofilms; antimicrobials; interkingdom interactions

\section{Introduction}

Endodontic infection, in the form of biofilms, have been visualised colonising necrotic and treated root canals [1-3]. It has been evidenced that root canal infections exist as complex polymicrobial communities of bacteria and fungi [4]. Interkingdom interactions are highly relevant and should be considered in development of effective treatment strategies [4,5]. It is widely accepted that the chemo-mechanical means of disinfection during root canal treatment can be hampered by the intricate anatomy of the root canal system [6]. Therefore, despite chemo-mechanical disinfection, a significant challenge faced by dental cements used in the filling of the root canal space is the presence of persistent microorganisms [7].

In response to the challenges faced in sealing the root canal space, calcium-silicatebased materials have grown in prominence. The first member of the calcium-silicate-based materials to be introduced was mineral trioxide aggregate (MTA). MTA principally consists of tricalcium silicate, dicalcium silicate, tricalcium aluminate and tetracalcium aluminoferrite with bismuth oxide powder added as a radiopacifying agent [8]. Subsequently, a variety of new formulations of purer calcium-silicate-based materials have been developed 
based on tricalcium silicate chemistry [9]. These are termed bioceramics and are used primarily in endodontics [10]. Amongst this group of materials is Biodentine. These materials are indicated for a variety of endodontic procedures, including perforation repairs, regenerative endodontic procedures, retrograde obturation, vital pulp therapy and management of immature permanent teeth, similar applications to those outlined for MTA [11]. Previous studies have shown that these materials possess antibacterial and antifungal properties against isolated bacterial and fungal species. The antibacterial efficacy of the calcium silicate materials has been attributed to the alkaline environment formed when calcium silicate undergoes hydrolysis in water, producing calcium silicate hydrate and calcium hydroxide. The presence of precipitated calcium hydroxide results in an alkaline $\mathrm{pH}[12,13]$. While this appears a useful function of the materials, there are limitations on the applicability of studies of this phenomenon. Many of these studies used material suspensions, in either media or sterile water, to test activity against only planktonic microbial cells, with the assessments based on determining minimum inhibitory concentrations (MIC) or suspension turbidity [14-16]. Such methods do not mimic the situation seen in clinical scenarios where it has been shown that microbes exist within biofilms, displaying unique phenotypic characteristics compared to their free-floating planktonic counterparts, including a notorious tolerance to antimicrobial agents under laboratory conditions $[17,18]$. Moreover, as highlighted, these studies use only mono-species systems that do not fully represent the polymicrobial nature of the infected root canal [19-24]. Confirming the importance of assessing the effect on biofilms, Jardine, Montagner [25], using an ex vivo biofilm model, demonstrated that calcium silicate materials were not effective against multispecies microcosm biofilms, even after 7 days of incubation. Therefore, our study suggests the need for augmenting materials with anti-biofilm active agents.

Chitosan is a modified natural carbohydrate polymer produced by deacetylation of chitin [26]. Chitosan is seen as a promising antimicrobial agent [27]. It is known to possess antimicrobial activities against a variety of Gram-positive and Gram-negative bacteria $[28,29]$ and fungi $[30,31]$. The antimicrobial mechanism of action of chitosan is still unclear. However, it may be attributed to the affinity of the positively charged chitosan molecules for the negatively charged microbial plasma membrane which supports the interaction with anionic components of the cell membrane and leads to cell membrane disruption, intracellular contents leakage and ultimately cell death [31,32]. These properties lend themselves to the development of chitosan-based endodontic materials. Indeed, a previous study has highlighted the antibacterial effectiveness of chitosan nanoparticles (CNps) when incorporated into $\mathrm{Ca}(\mathrm{OH})_{2}$ pastes used as endodontic medicaments [33]. Other studies have shown that the antimicrobial effect of calcium-silicate-based sealers was enhanced by the incorporation of chitosan nanoparticles (CNps) in root canal sealers [29,34]. We and others have also shown the antimicrobial effectiveness of chitosan when used as a root canal irrigant $[30,35,36]$. Therefore, in the current study, we aimed to assess the anti-biofilm effects against complex polymicrobial biofilms of chitosan when incorporated into endodontic calcium silicate cements.

\section{Results}

\subsection{Unmodified Calcium-Silicate-Based Materials Demonstrate Minimal Antimicrobial Effects in Comparison to Dentine}

Biofilm regrowth and composition on dentine, MTA and Biodentine discs was assessed using live/dead qPCR. It was evident that both MTA and Biodentine did not show an ability to inhibit biofilm regrowth of any of the biofilm models after $24 \mathrm{~h}$ of incubation, compared to the control dentine discs (Figure 1A-C). Notably, the colony-forming equivalent (CFE) for Candida and bacteria formed on controls (dentine discs) were approximately $1 \times \log _{10}$ less when compared with colonies formed on the tested materials, although this did not reach statistical significance for viable cells. 
A

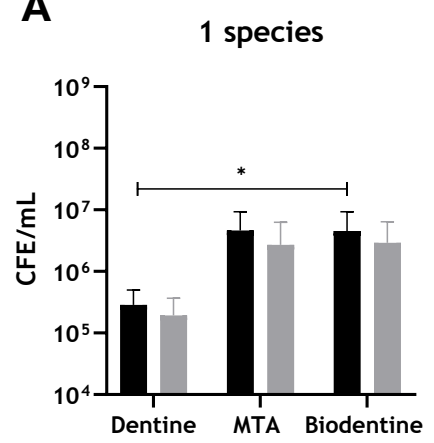

B

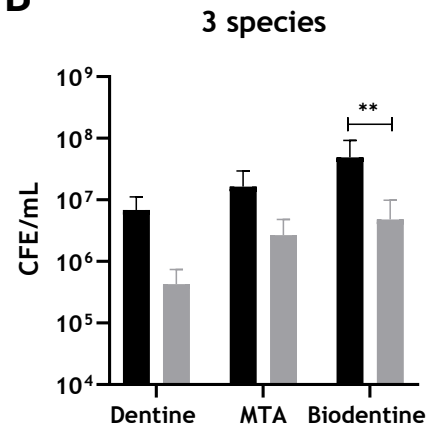

C

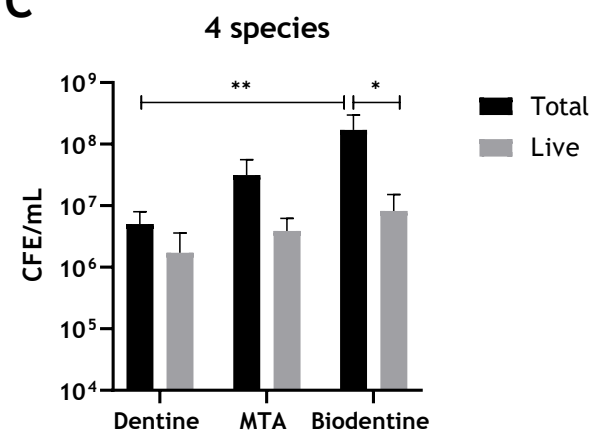

Figure 1. Compositional analysis of biofilms on MTA, Biodentine and bovine dentine discs. Biofilms were grown and assessed using live/dead qPCR. (A) Total and live CFE/mL of C. albicans-only biofilms, (B) Total and live CFE/mL of 3-species bacterial-only biofilms (S. gordonii, P. gingivalis and F. nucleatum). (C) Total and live CFE/mL of 4-mixed biofilms (bacteria and C. albicans). Data were analysed by Kruskal-Wallis with Dunn's tests to determine the $p$ values for nonparametric multiple comparisons. Differences were considered statistically significant when $p<0.05$. ${ }^{*}$ Indicates statistically significant differences $\left({ }^{*} p<0.05,{ }^{* *} p<0.01\right)$. Data representative of biofilms from three independent repeats $\mathrm{n}=3$ with 3 technical replicates.

When determining the potential effect of interkingdom interactions, there was approximately a 3.5 -fold increase in viable bacteria when C. albicans was present on a dentine substrate $\left(4.28 \times 10^{5}\right.$ compared to $\left.1.48 \times 10^{6} \mathrm{CFE}\right)$, while on Biodentine, a much smaller 1.4-fold increase was apparent with respect to bacterial numbers in the absence of $C$. albicans. Meanwhile, no change was noted for bacterial loads on an MTA substrate (Figure 2). The results indicate that inclusion of $C$. albicans may support bacterial biofilm formation on a biological substrate. However, there were no or little supportive effects of $C$. albicans on bacterial numbers on abiotic surfaces. In contrast, on a dentine substrate, viable $C$. albicans showed a slight 1.2-fold increase when bacteria were incorporated, while an approximate 2-fold decrease was found in C. albicans CFE when grown on MTA and Biodentine in the presence of bacteria (Figure 2). These results might suggest some level of interkingdom antagonistic interactions with bacteria inhibiting C. albicans on abiotic surfaces. Total and live CFE counts for all biofilms and biofilm composition (\%) for bacteria and C. albicans in each mixed biofilm are shown in Table 1.

Table 1. Percentage composition of mixed-species biofilm model and total and live CFE counts for C. albicans and bacteria in all biofilms following biofilm growth on unaltered MTA, Biodentine and dentine substrates.

\begin{tabular}{ccccccc}
\hline & \multicolumn{3}{c}{ 4-Species Model } & 3-Species Model & Mono-Species Model \\
\cline { 2 - 6 } & Bacteria & $\mathbf{( \% )}{ }^{*}$ & C. albicans & $\mathbf{( \% )}{ }^{*}$ & Bacteria & C. albicans \\
\hline Dentine (Total) & $4.54 \times 10^{6}$ & 90.21 & $4.92 \times 10^{5}$ & 9.79 & $6.84 \times 10^{6}$ & $2.85 \times 10^{5}$ \\
Dentine (Live) & $1.48 \times 10^{6}$ & 86.04 & $2.40 \times 10^{5}$ & 13.96 & $4.28 \times 10^{5}$ & $1.93 \times 10^{5}$ \\
MTA (Total) & $2.90 \times 10^{7}$ & 92.0 & $2.53 \times 10^{6}$ & 8.0 & $1.63 \times 10^{7}$ & $4.62 \times 10^{6}$ \\
MTA (Live) & $2.696 \times 10^{6}$ & 69.17 & $1.20 \times 10^{6}$ & 30.83 & $2.68 \times 10^{6}$ & $2.70 \times 10^{6}$ \\
Biodentine (Total) & $1.66 \times 10^{8}$ & 97.01 & $5.10 \times 10^{6}$ & 2.99 & $4.90 \times 10^{7}$ & $4.52 \times 10^{6}$ \\
Biodentine (Live) & $6.60 \times 10^{6}$ & 80.16 & $1.63 \times 10^{6}$ & 19.84 & $4.81 \times 10^{6}$ & $2.92 \times 10^{6}$ \\
\hline
\end{tabular}

* Average percentage composition of bacteria and C. albicans in mixed-species biofilms. 


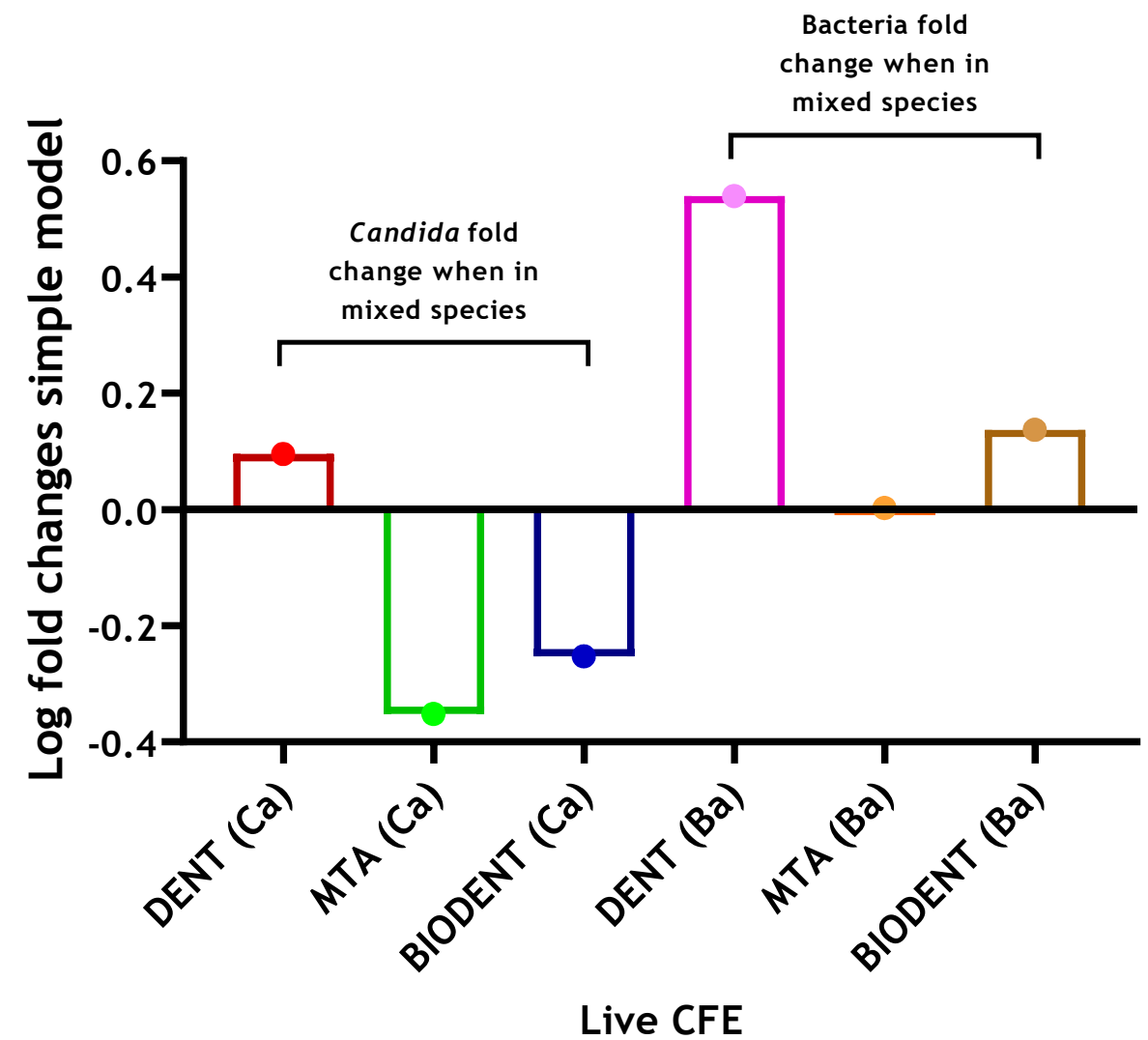

Figure 2. Log fold changes of live yeast and bacteria in complex 4-species biofilm model on three different materials. C. albicans and bacteria were quantified $(\mathrm{CFE} / \mathrm{mL})$ in mixed-species biofilms (4 species) and compared to simpler models of C. albicans-only biofilms (1 species) and bacterial-only biofilms (3 species), respectively. Log fold changes were calculated and presented graphically. Data representative from three repeats with 3 technical replicates.

\subsection{Addition of Chitosan Confers Antimicrobial Properties on Biodentine, but Not MTA}

The addition of chitosan to MTA imparted no antimicrobial enhancement against any of the biofilm models used (Figure 3A-C). Interestingly, in multispecies biofilms, CFE counts increased by $54.5 \%$ and $22 \%$ with the addition of $2.5 \%$ and $5 \%$ chitosan, respectively, when compared to unaltered MTA (Figure 3C). In contrast, for Biodentine, when C. albicans was grown as a mono-species biofilm, the live CFE following $2.5 \mathrm{wt} \%$ and $5 \mathrm{wt} \%$ chitosan incorporations was reduced by $83 \%$ and $71 \%$, respectively, compared to the unmodified Biodentine. However, this reduction was not statistically significant (Figure $4 \mathrm{~A}$ ). In contrast, the addition of $2.5 \%$ and $5 \%$ chitosan reduced the live CFE/mL of the three-species biofilm model (bacteria only) by $85 \%$ and $97 \%$, respectively, from $4.81 \times 10^{6} \mathrm{CFE} / \mathrm{mL}$ (unmodified material) to $7.12 \times 10^{5}$ and $1.42 \times 10^{5} \mathrm{CFE} / \mathrm{mL}$. The microbial reduction was dose-dependent, and the greatest reduction observed at $5 \%$ chitosan was significant $(* * p<0.01)$. A decrease in bacterial load $(p>0.05)$ by $67 \%$ was also observed at 5\% compared to the control (bovine dentine) (Figure $4 \mathrm{~B}$ ). 
A

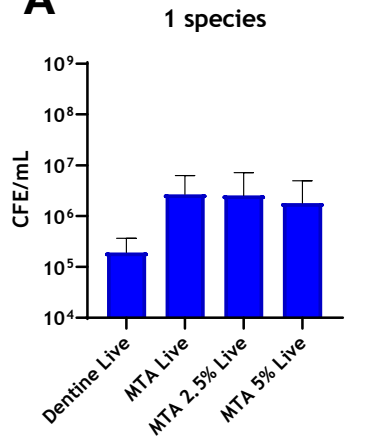

B



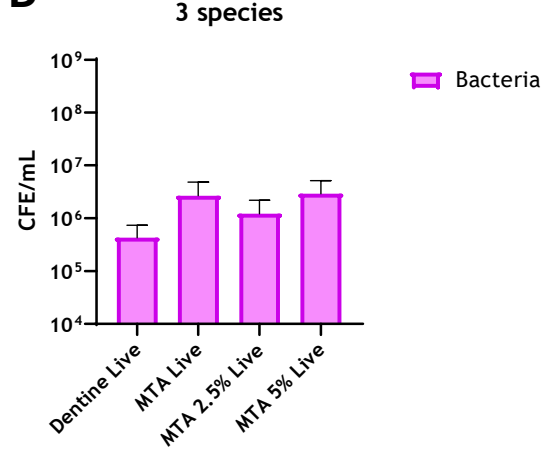

C

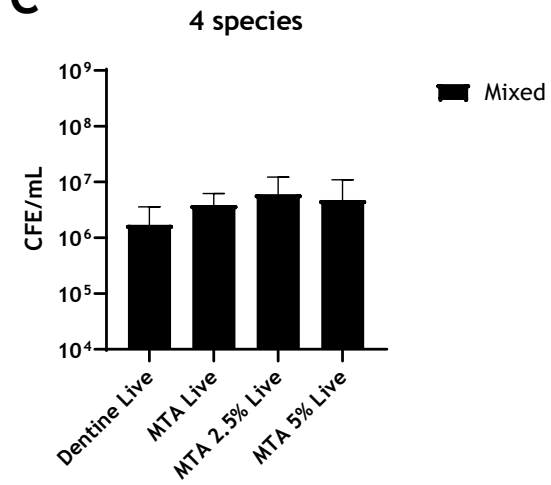

Figure 3. Compositional analysis of biofilms on MTA material discs. Live/dead qPCR was conducted following incorporation of $2.5 \mathrm{wt} \%$ and $5 \mathrm{wt} \%$ of chitosan: (A) Live CFE/mL of C. albicans-only biofilms, (B) Live CFE/mL of bacterial-only biofilms and (C) Live CFE/mL of 4-mixed biofilms (biofilms containing C. albicans). The bacterial and fungal loads were quantified using $16 \mathrm{~S}$ and $18 \mathrm{~S}$ primers, respectively. Bovine dentine and unaltered MTA discs were used as controls. Data were analysed by Kruskal-Wallis with Dunn's tests.

A

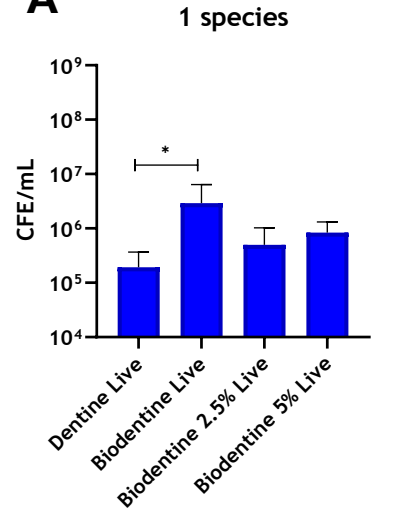

B

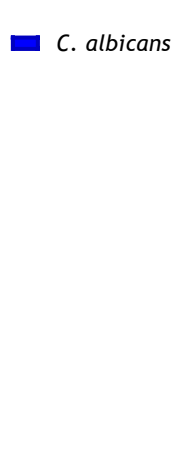

3 species

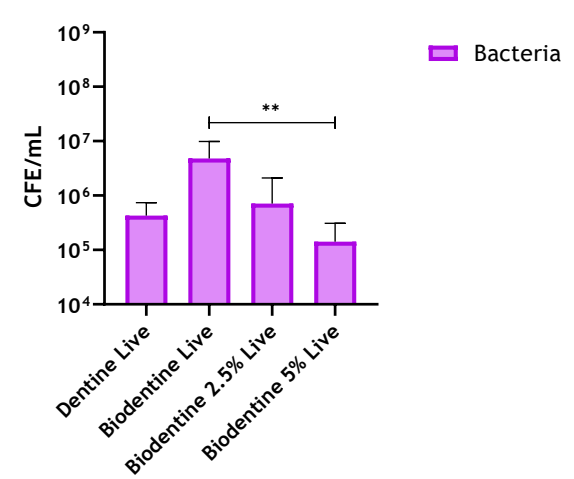

C

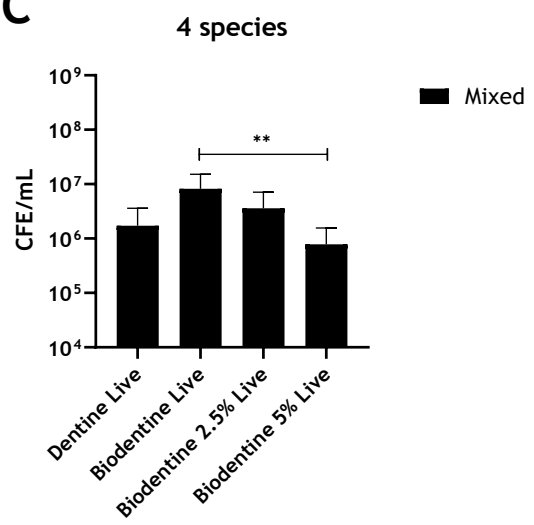

Figure 4. Compositional analysis of regrown biofilms on Biodentine material discs. Chitosan amounts of $2.5 \mathrm{wt} \%$ and $5 \mathrm{wt} \%$ were incorporated into Biodentine material, and live/dead qPCR was performed on (A) Live CFE/mL of C. albicans biofilms, (B) Live CFE/mL of bacterial biofilms and (C) Live CFE/mL of 4-mixed biofilms (bacteria and Candida). Bovine dentine and unaltered Biodentine discs were used as controls. Data were analysed by Kruskal-Wallis with Dunn's tests. * Indicates statistically significant differences $\left({ }^{*} p<0.05,{ }^{* *} p<0.01\right)$.

For the four-species biofilm model, adding $2.5 \%$ and $5 \%$ chitosan to Biodentine was able to effectively reduce live CFE by $56 \%$ and $90.5 \%$, respectively, compared to the unaltered Biodentine (Figure $4 \mathrm{C}$ ). The reduction from $8.24 \times 10^{6} \mathrm{CFE} / \mathrm{mL}$ in the unaltered material to $3.6 \times 10^{6}$ and $7.8 \times 10^{5} \mathrm{CFE} / \mathrm{mL}$ in the chitosan-treated material $(2.5 \%$ and $5 \%$, respectively) was significant in the $5 \%$ added material $(* * p 0.01)$. A decrease in the live CFE $/ \mathrm{mL}$ of the mixed biofilm $(p>0.05)$ by $\sim 55 \%$ was also observed at $5 \%$ compared to the control (bovine dentine). Of interest, the addition of chitosan preferentially targeted C. albicans in mixed-species biofilms and a concomitant significant $\left({ }^{* *} p<0.01\right)$ inhibition of regrowth of four-species biofilms (Supplementary Figure S1B). In contrast, at $5 \%$ chitosan, the reduction of bacteria number was not significant $(p>0.05)$ when $C$. albicans was present (Supplementary Figure S1C). However, in biofilms omitting C. albicans, a significant decrease in bacterial load was observed (** $p<0.01$ ) at $5 \%$ chitosan $(4 \mathrm{~B})$.

In a similar trend, the CFE count of $C$. albicans grown on Biodentine with $2.5 \% \mathrm{CNPs}$ was decreased by approximately 2-fold when the three bacterial species were added. On the other hand, an approximate 12-fold reduction was noted for $C$. albicans on Biodentine with $5 \%$ CNPs $\left(8.39 \times 10^{5}\right.$ compared to $\left.6.79 \times 10^{4}\right)$, compared to C. albicans mono-species biofilm, in the presence of bacteria (Figure 5). However, the scenario was reversed with 4.7- and 
5 -fold increases of bacterial numbers observed at $2.5 \%$ and $5 \%$ CNPs, respectively, following inclusion of $C$. albicans (Figure 5). Live CFE counts for biofilms grown on Biodentine with $2.5 \%$ and $5 \%$ chitosan and biofilm composition (\%) for bacteria and C. albicans in each mixed biofilm are shown in Table 2 .

Table 2. Live CFE counts for C. albicans and bacteria and percentage composition in all biofilms following biofilm growth on Biodentine discs.

\begin{tabular}{ccccccc}
\hline & & \multicolumn{2}{c}{ 4-Species Model } & & 3-Species Model & Mono-Species Model \\
\cline { 2 - 7 } & Bacteria & $\mathbf{( \% ) *}$ & C. albicans & $\mathbf{( \% )}{ }^{*}$ & Bacteria & C. albicans \\
\hline Biodentine & $6.60 \times 10^{6}$ & 80.16 & $1.63 \times 10^{6}$ & 19.84 & $4.81 \times 10^{6}$ & $2.92 \times 10^{6}$ \\
$\begin{array}{c}\text { (unaltered) } \\
\text { Biodentine (2.5\%) }\end{array}$ & $3.33 \times 10^{6}$ & 92.22 & $2.81 \times 10^{5}$ & 7.78 & $7.124 \times 10^{5}$ & $4.98 \times 10^{5}$ \\
Biodentine (5\%) & $7.120 \times 10^{5}$ & 91.30 & $6.79 \times 10^{4}$ & 8.70 & $1.42 \times 10^{5}$ & $8.39 \times 10^{5}$ \\
\hline
\end{tabular}

* Average percentage composition of bacteria and C. albicans.

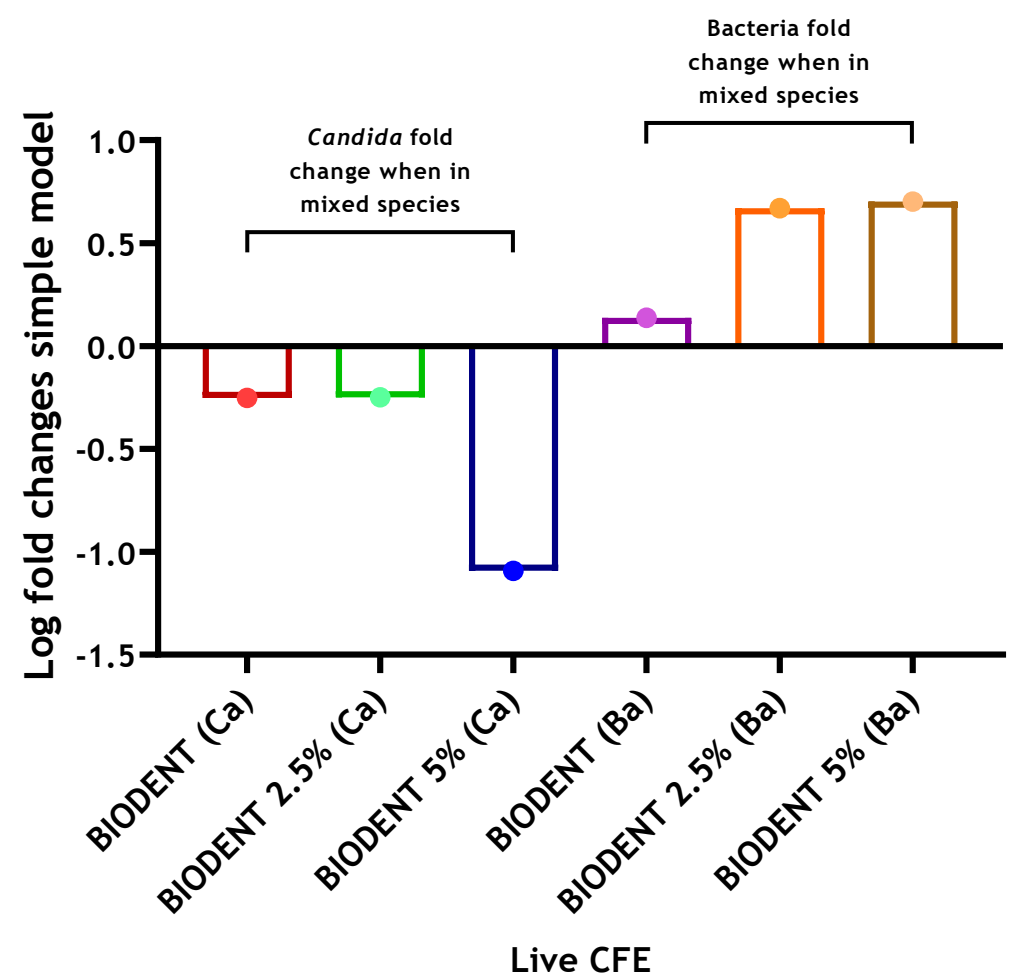

Figure 5. Log fold changes of live yeast and bacteria in complex 4-species biofilm model on Biodentine discs \pm chitosan. C. albicans and bacteria were quantified $(\mathrm{CFE} / \mathrm{mL})$ in mixed-species biofilms (4 species) and compared to simpler models of C. albicans-only biofilms (1 species) and bacterial-only biofilms (3 species), respectively. Log fold changes were calculated and presented graphically. Data representative from three repeats with 3 technical replicates.

\subsection{Addition of Chitosan Drives an Increase in $\mathrm{pH}$ for Biodentine but Not MTA}

Both unmodified MTA and Biodentine cements exhibited an increase in alkalinity as setting proceeds. The $\mathrm{pH}$ values for MTA and Biodentine at $24 \mathrm{~h}$ were 12.7 and 11.5, respectively. However, elevated $\mathrm{pH}$ was determined for Biodentine when chitosan was incorporated and in a dose-dependent manner. The measurements of $\mathrm{pH}$ for MTA and Biodentine were approximately 12.8 and 12.6, respectively, at $24 \mathrm{~h}$ when $5 \%$ chitosan was incorporated into both cements (Figure 6). The $\mathrm{pH}$ of the manufacturer-supplied liquid component was also assessed for Biodentine and was determined to be 3.7. 
Biodentine

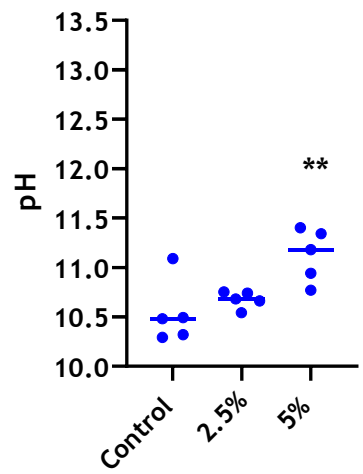

- $1 \mathrm{~h}$

MTA

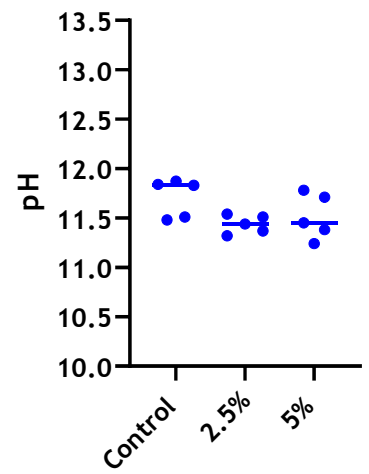

Biodentine

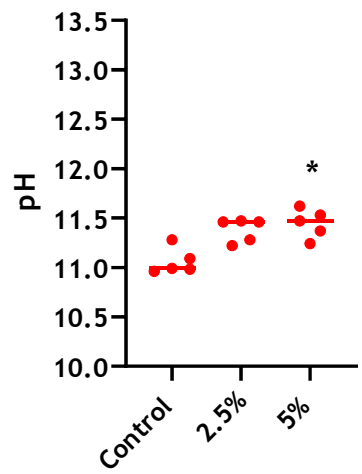

- $3 \mathrm{~h}$

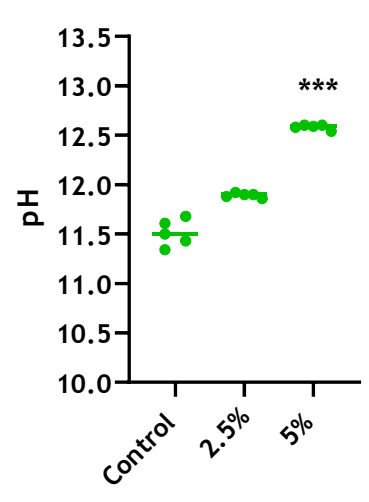

- $24 \mathrm{~h}$

Figure 6. $\mathrm{pH}$ evaluation of leachate from different bioceramics. $\mathrm{pH}$ values for distilled water in contact with MTA and Biodentine $+2.5 \mathrm{wt} \%$ and $5 \% \mathrm{wt} \% \mathrm{CNPs}$, were determined at $1 \mathrm{~h}, 3 \mathrm{~h}$ and $24 \mathrm{~h}$. Unmodified materials were used as controls. Data were analysed by Kruskal-Wallis with Dunn's tests. Statistically significant differences between the control and each time point are presented as ${ }^{*} p<0.05,{ }^{* *} p<0.01$ and ${ }^{* * *} p<0.001$.

\section{Discussion}

The introduction of calcium-silicate-based materials has been suggested as one of the most important advances in dental material science [37]. The antimicrobial properties of calcium-silicate-based materials have been widely investigated, though these studies are limited by their exploration of only single-species microbial models and the use of traditional microbiological techniques. The present study aims to close the gap in the literature, creating an understanding of the antimicrobial activities of these materials within a more relevant microbiological model system. Streptococcus, Fusobacterium and Porphyromonas are amongst the most frequently isolated bacterial species from endodontic infections [38]. Candida spp. has been shown to have a prevalence of $8.2 \%$ in endodontic infections [39]. Here, we were able to show for the first time that chitosan could be incorporated into Biodentine and effectively inhibit biofilm formation, opening the door for exploration of effective antimicrobial strategies for prevention and management of endodontic infection. 
Our results indicated that neither material in an unmodified state shows an ability to inhibit biofilm regrowth of the three biofilm models after $24 \mathrm{~h}$ of incubation, compared to the control substrate of bovine dentine. The number of live C. albicans and bacterial colonies formed on both MTA and Biodentine were increased by approximately one log compared to those formed on dentine discs (Figure 1A,B), albeit without reaching statistical significance. This finding is interesting and raises the question as to whether dentine is demonstrating an antimicrobial effect in comparison to the cements, or if calcium silicate cements are supportive of microbial growth. Previous studies have demonstrated that dentine can enhance the antimicrobial effects of some materials and it has been hypothesised this is a result of changing the physicochemical nature of the materials with which dentine is combined [40,41]. However, in the present study, dentine was not combined with the materials. Therefore, it is not inconceivable that dentine itself as a biologically active substrate may have a weak antimicrobial capacity of its own. A previous study has demonstrated that the addition of a sterilised crushed human dentine to a suspension of E. faecalis did not exhibit any antibacterial activity [41]. However, in a separate study, it was shown that extracellular matrix isolated from the pulp and dentine of freshly extracted teeth demonstrated some level of antibacterial activity [42]. Another possibility is related to microbial adhesion. Type I collagen is the main organic component of dentine [43]. It has been suggested that collagen-rich substrates, such as dentine, can act as an ideal substrate for colonisation by Streptococci $[44,45]$. The preparation of dentine used in microbiological studies may have an effect on microbial adhesion [46]. In the present study, the hightemperature steam sterilisation used may have resulted in collagen denaturation, which has previously been suggested to reduce microbial adhesion [47]. In contrast, it has been demonstrated that dentinal collagen of bovine dentine slices, despite being partially denatured at high temperatures, can revert to its original confirmation [48]. Despite the potential confounding factors, it is felt that the use of dentine as a control substrate is appropriate. Previous studies have dispensed with biologically relevant substrates and used cell culture plastics as control surfaces for establishing the antimicrobial effect of this group of materials $[19,20]$. Although such in vitro biofilm systems have greatly enhanced our understanding of biofilm biology, their lack of biological and clinical relevance severely limits the understanding gleaned [49].

As stated, it was evident from the results that both unmodified ProRoot MTA and Biodentine were readily colonised by C. albicans and bacterial biofilms after $24 \mathrm{~h}$ of incubation. Neither material demonstrated antimicrobial properties against $C$. albicans, bacterial or interkingdom biofilms compared to the dentine control. It was clear from the findings that inclusion of bacteria inhibits Candida regrowth on both materials, whilst the addition of C. albicans showed a degree of enhancement of bacterial growth on these materials. Antagonistic interkingdom interactions have previously been highlighted where F. nucleatum and a number of other bacterial species including Streptococci and P. gingivalis inhibit growth and hyphal morphogenesis of C. albicans [50,51]. On the other hand, on the dentine substrate, the inclusion of Candida increased the number of viable bacteria by approximately 3.5-fold, while the addition of bacteria showed a small 1.2-fold increase in viable C. albicans. The mechanism may mirror the findings of Kean, Rajendran [52], albeit with $S$. aureus, where a strong synergy exists through the physical scaffold of hypha, providing a niche for colonisation a phenomenon that has been termed "mycofilms". The microbial interactions differ according to substrate on which the interaction occurs. Such substrate-dependent phenomena have been described in other interkingdom interactions. Antagonistic interactions between E. faecalis and C. albicans in in vitro and in vivo models have been previously described [5,53]. However, Krishnamoorthy, Lemus [54] highlighted synergistic interactions between these species in an oral epithelium model.

The addition of chitosan to MTA provided no enhancement against the biofilm models after $24 \mathrm{~h}$ of incubation. In contrast, the combination of chitosan and Biodentine reduced the live colony-forming equivalent of the bacterial and mixed-species biofilms significantly. Notably, chitosan affected the composition of the evaluated four-species biofilms, causing 
a significant reduction in the viable fungal load in mixed culture. Interestingly, in the presence of $C$. albicans, bacterial load was decreased, but not significantly; in contrast, bacteria were decreased significantly when $C$. albicans was absent. These results indicate that fungi may confer protection to bacteria from active agents when grown in mixed microbial culture. This is in line with that described by Young, Alshanta [55], where protection to antimicrobial challenge is conferred upon bacterial species in the presence of $C$. albicans. It has also been shown that $C$. albicans ECM protected S. aureus against vancomycin treatment, possibly by limiting or delaying drug diffusion to $S$. aureus [56].

It is clear from our findings that ProRoot MTA and Biodentine exhibited different antimicrobial behaviours when chitosan was added. One mechanism by which calcium silicate cements have been said to exert an antimicrobial effect is through modifying environmental $\mathrm{pH}$. It has been postulated that increased alkalinity, resulting from the release of calcium hydroxide upon setting of MTA preparations and its subsequent dissociation into calcium and hydroxide ions, may be responsible for any observed antimicrobial action $[57,58]$. To understand if the addition of chitosan modified $\mathrm{pH}$, measurements of both materials' leachate were taken. The unmodified MTA exhibited greater alkalinity than unmodified Biodentine at all time points assessed. This could be a result of differences observed in the $\mathrm{pH}$ of the manufacturer-supplied liquid components of both MTA ( $\mathrm{pH} 7)$ and Biodentine ( $\mathrm{pH}$ 3.7). It was also established that the addition of chitosan to MTA made no appreciable difference in $\mathrm{pH}$ at $24 \mathrm{~h}$. However, upon addition of chitosan to Biodentine, a significant increase in $\mathrm{pH}$ was observed. This increase occurred in a dose-dependent manner. Given that the $\mathrm{pH}$ change merely brings it in line with that of MTA, it is unlikely that $\mathrm{pH}$ alone accounts for the antimicrobial activity differences seen between the two materials. However, in contrast to MTA, the increase in $\mathrm{pH}$ observed for modified Biodentine cement indicates that there may be an interaction between the cement components and the solid form of the chitosan particulate system. It has been shown that acidic chitosan solution displays a stronger antibacterial activity against $E$. coli than that of more alkaline solutions [59]. Other studies have shown higher antimicrobial activities when $\mathrm{pH}$ values of the chitosan solution ranged between 5 and 6.5-7; however, the inhibitory effect was completely abolished at $\mathrm{pHs}$ greater than $7[60,61]$. It has been suggested that the surrounding acidic medium leads to protonation of amino groups $\left(\mathrm{NH}_{2}\right)$ of chitosan, which subsequently favours electrostatic interactions between the formed positively charged chitosan molecules and negative residues at biological sites [59,62]. Accordingly, the acidic $\mathrm{pH}$ of the manufacturer-supplied Biodentine liquid may have "activated" the chitosan, resulting in enhanced antimicrobial activity of the new compound.

\section{Materials and Methods}

\subsection{Growing Multi-Species Biofilms}

An established interkingdom endodontic biofilm model, previously described by our group, was used throughout this study [36]. Briefly, biofilms containing Candida albicans SC5314 (ATCC MYA-2876), Streptococcus gordonii (ATCC 35105), Porphyromonas gingivalis (ATCC 33277) and Fusobacterium nucleatum (ATCC 10953) were constructed. C. albicans was grown on Sabouraud's dextrose agar (SAB) at $30^{\circ} \mathrm{C}$ aerobically for $24-48 \mathrm{~h}$; S. gordonii was grown on Columbia agar supplemented with $5 \%$ horse blood (CBA) at $37^{\circ} \mathrm{C}$ in $5 \% \mathrm{CO}_{2}$ for $24 \mathrm{~h}$. The other two anaerobic organisms were maintained on fastidious anaerobic agar (FAA) plates containing $5 \%$ defibrinated horse blood at $37^{\circ} \mathrm{C}$ in an anaerobic chamber (Don Whitley Scientific Limited, Bingley, UK) with an atmosphere of $85 \% \mathrm{~N}_{2}, 10 \% \mathrm{CO}_{2}$ and $5 \% \mathrm{H}_{2}$ for 24-48 h. All agar bases were supplied by Oxoid, UK. Standardised cultures of $C$. albicans and bacteria (S. gordonii, P. gingivalis and F. nucleatum) standardised at $1 \times 10^{8} \mathrm{CFU} / \mathrm{mL}$ were first diluted to $1 \times 10^{6} \mathrm{CFU} / \mathrm{mL}$ and $1 \times 10^{7} \mathrm{CFU} / \mathrm{mL}$ in culture broth, respectively. The broth consisted of 1:1 mixture of Roswell Park Memorial Institute-1640 (RPMI) with Todd Hewitt Broth (THB) supplemented with $0.01 \mathrm{mg} / \mathrm{mL}$ hemin and $2 \mu \mathrm{g} / \mathrm{mL}$ menadione. Four mixed-species biofilms were grown in pre-sterilised polystyrene 24-well flat-bottom plates $\left(\right.$ Costar $^{\circledR}$, Corning Incorporated, Corning, NY, USA) for $24 \mathrm{~h}$ in $5 \% \mathrm{CO}_{2}$ at $37^{\circ} \mathrm{C}$. 
Two derived models were also used in parallel, one of which contained bacterial species only (S. gordonii, P. gingivalis and F. nucleatum) and one contained C. albicans only. This was to assess the importance of $C$. albicans in maintaining biofilm tolerance or otherwise.

\subsection{Preparation of ProRoot MTA and Biodentine Materials \pm Chitosan}

Bovine dentine was used, which is an appropriate substitute for human dentine due to its availability and its great similarity to the human dentine [63]. Bovine dentine discs (Modus Laboratories, Reading, UK) were of $7 \mathrm{~mm}$ in diameter, $1 \mathrm{~mm}$ in thickness, with perpendicular dentinal tubule orientation (transverse cross section) and polished to 2500 micron on one side. The dentine discs were autoclaved at $122^{\circ} \mathrm{C}$, before use, for $16 \mathrm{~min}$. Two bioceramic cements were used: mineral trioxide aggregate (MTA) (ProRoot MTA Root Repair Material (Dentsply Tulsa Dental Specialties, Johnson City, USA)) and Biodentine (Septodont, Saint-Maur-des-Fossés, France) (Table 3). Moulds, $1 \mathrm{~mm}$ in height with $7 \mathrm{~mm}$ diameter corresponding to the size of the bovine dentine discs, were fabricated from dental silicone-based impression materials; putty soft (Coltene, Altstätten, Switzerland); and polyvinyl siloxane impression material (Extrude, Romulus, MI, USA). The moulds were then disinfected with $70 \%$ ethanol. MTA and Biodentine powders were mixed according to the manufacturer. MTA powder was mixed with a ProRoot liquid micro-dose ampoule. The powder-containing capsule of Biodentine ${ }^{\mathrm{TM}}$ was mixed with 5 drops of the Biodentine ${ }^{\mathrm{TM}}$ Liquid.

To investigate the effect of chitosan on the antimicrobial properties of tested materials, chitosan was incorporated into MTA and Biodentine. Medium molecular weight Chitosan (CS (Sigma-Aldrich, St. Louis, MO, USA)) was used throughout this study. Briefly, chitosan powder was disinfected using UV for $15 \mathrm{~min}$. Following this, the chitosan powder was incorporated into the Biodentine ${ }^{\mathrm{TM}}$ and MTA powders using two different concentrations $(2.5 \mathrm{wt} \%$ and $5 \mathrm{wt} \%)$ and resultant powder was mixed with the manufacturer liquid component. Materials were then placed into aseptic moulds and allowed to set in a moist atmosphere at $37^{\circ} \mathrm{C}$ for $3 \mathrm{~h}$ and $1 \mathrm{~h}$, respectively.

Table 3. Composition of ProRoot MTA and Biodentine.

\begin{tabular}{ccc}
\hline Product & Composition & Manufacturer \\
\hline $\begin{array}{c}\text { White ProRoot Mineral Trioxide } \\
\text { Aggregate (W-MTA) }\end{array}$ & $\begin{array}{c}\text { Powder: tricalcium silicate, dicalcium silicate, } \\
\text { bismuth oxide, tricalcium aluminate, calcium } \\
\text { sulphate dihydrate or gypsum. } \\
\text { Liquid: water }\end{array}$ & $\begin{array}{c}\text { Dentsply Tulsa Dental Specialties, } \\
\text { Johnson City, WA, USA }\end{array}$ \\
& $\begin{array}{c}\text { Powder: tricalcium silicate, dicalcium silicate, } \\
\text { calcium carbonate, zirconium oxide, calcium } \\
\text { Biodentine }\end{array}$ & $\begin{array}{c}\text { Septodont, Saint-Maur-des-Fossés, } \\
\text { Liquid: calcium chloride, a hydrosoluble } \\
\text { (water-soluble) polymer, water. }\end{array}$ \\
\hline
\end{tabular}

\subsection{Quantitative Analysis of Biofilms Formed on ProRoot MTA and Biodentine Materials \pm Chitosan}

The antimicrobial ability of ProRoot MTA and Biodentine was assessed against biofilm regrowth on the materials placed in a 24-well plate. Bovine dentine discs were used as positive controls. Four-species, three-species (bacteria only) and mono-species (C. albicans only) biofilms were grown in RPMI/THB in 24-well plates for $24 \mathrm{~h}$, as previously described. After incubation, the spent biofilm media was discarded, and biofilms were washed with PBS, mechanically disrupted in $1 \mathrm{~mL}$ of media and diluted to 1:10 in fresh RPMI/THB and then inoculated on MTA and Biodentine discs (unaltered materials and altered ones with chitosan) into 24-well plates. Mechanical disruption of the biofilms serves the purpose of simulating mechanical debridement of the root canal. Plates were then incubated for an additional $24 \mathrm{~h}$ in $5 \% \mathrm{CO}_{2}$ at $37{ }^{\circ} \mathrm{C}$ to allow biofilm growth. 
Following incubation, each disc was washed with PBS, sonicated and transferred into a bijoux tube containing $1 \mathrm{~mL}$ PBS and then sonicated at $35 \mathrm{kHz}$ in a sonic bath for $10 \mathrm{~min}$. The sonicate was then transferred to $1.5 \mathrm{~mL}$ Eppendorf tubes (Greiner Bio-one, Kremsmünster, Austria, UK) for DNA extraction. The composition of the regrown biofilms on dentine, MTA and Biodentine discs was assessed using live/dead qPCR, a technique that uses propidium monoazide (PMA), a DNA-intercalating dye, to differentiate biofilm viable and dead microorganisms. Samples were prepared as previously described by [64]. Briefly, each sonicated sample was equally split; samples to be treated with PMA and control samples without PMA. Following this, $5 \mu \mathrm{L} / \mathrm{mL}$ of $50 \mu \mathrm{M}$ PMA dye was added to each sample and incubated in the dark for $10 \mathrm{~min}$. Treated and control samples were all incubated in the dark at room temperature for $10 \mathrm{~min}$ to allow cells to uptake the dye. Samples were then exposed to a $650 \mathrm{~W}$ halogen light and positioned $20 \mathrm{~cm}$ away from the sample tubes, for $5 \mathrm{~min}$. During exposure, samples were placed on a bed of ice to avoid excessive heating. Following this, DNA extraction and real-time quantitative analysis were carried. Briefly, DNA was extracted from samples, according to manufacturer's instructions, using the QIAamp DNeasy Mini Kit (Qiagen, Manchester, UK). Biofilm compositional analysis were enumerated using real time qPCR using SYBR ${ }^{\circledR}$ GreenER ${ }^{\mathrm{TM}}$, with forward and reverse primers for either bacterial or Candida species, as listed in Table 4. qPCR was performed using the StepOnePlus ${ }^{\mathrm{TM}}$ Real-Time PCR system (Applied Biosystems, Waltham, MA, USA), and data analysed using the StepOnePlus software version 2.3 (ThermoFisher, Paisley, UK). All samples were run in duplicate with negative controls (master mix only) to assess for DNA contamination. The colony-forming equivalent (CFE) of samples was calculated using a previously established standard curve methodology [65] of serially extracted DNA bacterial and fungal colony-forming units from $1 \times 10^{4}$ to $10^{8} \mathrm{CFU} / \mathrm{mL}$. All experiments were performed three times, with three technical replicates.

Table 4. Primer sequences used for compositional analysis of biofilm models.

\begin{tabular}{|c|c|c|c|}
\hline Organism & Primer & Forward Primer $5^{\prime}-3^{\prime}$ & Reverse Primer $5^{\prime}-3^{\prime}$ \\
\hline C. albicans & $18 \mathrm{~S}$ & CTCGTAGTTGAACCTTGGGC & GGCCTGCTTTGAACACTCTA \\
\hline Bacteria & $16 S$ & TCCTACGGGAGGCAGCAGT & GGACTACCAGGGTATCTAATCCTGTT \\
\hline
\end{tabular}

\subsection{Evaluation of $\mathrm{pH}$ of Leachate}

Material discs $1 \mathrm{~mm}$ in thickness with $7 \mathrm{~mm}$ diameter were prepared of Biodentine and ProRoot MTA. Chitosan powder was incorporated into both materials at concentration of $2.5 \%$ and $5 \%$ by weight. The materials were allowed to set in a moist atmosphere at $37^{\circ} \mathrm{C}$ for $3 \mathrm{~h}$ and $1 \mathrm{~h}$, respectively. Each disc was then placed in a bijoux tube containing $3 \mathrm{~mL}$ sterile water. All samples were kept in a $5 \% \mathrm{CO}_{2}$ incubator at $37^{\circ} \mathrm{C}$. Measurement of $\mathrm{pH}$ change of the storage solution was taken using a calibrated $\mathrm{pH}$ meter (Mettler Toledo, Leicester, UK) at the following time points: 1, 3 and $24 \mathrm{~h}$. The $\mathrm{pH}$ measurement of the manufacturer Biodentine liquid was also taken.

\subsection{Statistical Analysis}

Data distribution, graphs and statistical analysis were performed using GraphPad Prism version 8 (GraphPad, San Diego, CA, USA). A D'Agostino-Pearson omnibus normality test was used before analysis to assess data distributions. Kruskal-Wallis with Dunn's tests were used to determine the $p$ values for non-parametric multiple comparisons (where data was not normally distributed). Differences were considered statistically significant when $p<0.05$.

\section{Conclusions}

The present study demonstrates limited intrinsic antimicrobial abilities for the tested calcium silicate cements. This contrasts with previous studies but is likely a result of the use of multi-species biofilm models in the present study. This further highlights the 
need for the use of appropriate model systems in assessment of therapeutics to account for the often synergistic/protective relationships that exist in complex microbiological systems. The present study highlights the potential to enhance the biological properties of an existing calcium silicate cement, which may serve to reduce the likelihood of persistence or re-establishment of infections within the treated root canal space. Although some insight may have been gained into the mechanism through improvements in antimicrobial effects, further work is needed to fully elucidate this mechanism and understand the contribution of chitosan. Clearly, the modification of Biodentine to enhance antimicrobial properties has the potential to modify physical properties which may affect clinical handling and appropriateness. Further studies into material characteristics will be required to assess the use of chitosan as an active antimicrobial supplement in calcium silicate cements.

Supplementary Materials: The following are available online at https:/ / www.mdpi.com/article / 10.3390/antibiotics10111317/s1, Figure S1: Compositional analysis of regrown biofilms on Biodentine material discs.

Author Contributions: S.A., J.L.B., C.D., M.C.B. and M.T. participated in study design, experimental procedures and were responsible for preparation of the manuscript. S.A., J.A.S., G.R. and W.M. conceived the study, participated in study design and were responsible for producing the final manuscript. All authors have read and agreed to the published version of the manuscript.

Funding: This research was funded by the BBSRC Industrial GlaxoSmithKline CASE PhD studentship for Christopher Delaney (BB/P504567/1) and Mark C. Butcher (BB/V509541/1).

Data Availability Statement: Data is contained within the article or supplementary material.

Conflicts of Interest: The authors declare no conflict of interest.

\section{References}

1. Ricucci, D.; Siqueira, J.F., Jr.; Bate, A.L.; Ford, T.R.P. Histologic investigation of root canal-treated teeth with apical periodontitis: A retrospective study from twenty-four patients. J. Endod. 2009, 35, 493-502. [CrossRef] [PubMed]

2. Ricucci, D.; Siqueira, J.F., Jr. Biofilms and apical periodontitis: Study of prevalence and association with clinical and histopathologic findings. J. Endod. 2010, 36, 1277-1288. [CrossRef] [PubMed]

3. Ricucci, D.; Siqueira, J.F., Jr.; Loghin, S.; Lin, L.M. Pulp and apical tissue response to deep caries in immature teeth: A histologic and histobacteriologic study. J. Dent. 2017, 56, 19-32. [CrossRef]

4. Persoon, I.F.; Buijs, M.J.; Özok, A.R.; Crielaard, W.; Krom, B.P.; Zaura, E.; Brandt, B.W. The mycobiome of root canal infections is correlated to the bacteriome. Clin. Oral Investig. 2017, 21, 1871-1881. [CrossRef] [PubMed]

5. Alshanta, O.A.; Alqahtani, S.; Shaban, S.; Albashaireh, K.; McLean, W.; Ramage, G. Comparison of Three Endodontic Irrigant Regimens against Dual-Species Interkingdom Biofilms: Considerations for Maintaining the Status Quo. Antibiotics 2020, 9, 634. [CrossRef]

6. Siqueira, F.J.; Rôças, I.N.; Ricucci, D. Internal tooth anatomy and root canal instrumentation. In The Root Canal Anatomy in Permanent Dentition; Springer: Berlin/Heidelberg, Germany, 2019; pp. 277-302.

7. Farrugia, C.; Baca, P.; Camilleri, J.; Moliz, M.A. Antimicrobial activity of ProRoot MTA in contact with blood. Sci. Rep. 2017, 7, 41359. [CrossRef]

8. Torabinejad, M.; White, D.J. Tooth Filling Material and Method of Use. U.S. Patent 5,415,547, 16 May 1995.

9. Camilleri, J. Mineral trioxide aggregate: Present and future developments. Endod. Top. 2015, 32, 31-46. [CrossRef]

10. Camilleri, J. Current Classification of Bioceramic Materials in Endodontics. In Bioceramic Materials in Clinical Endodontics; Springer: Berlin/Heidelberg, Germany, 2021; pp. 1-6.

11. Camilleri, J. Characterization and Properties of Bioceramic Materials for Endodontics. In Bioceramic Materials in Clinical Endodontics; Springer: Berlin/Heidelberg, Germany, 2021; pp. 7-18.

12. Camilleri, J. Characterization and hydration kinetics of tricalcium silicate cement for use as a dental biomaterial. Dent. Mater. 2011, 27, 836-844. [CrossRef]

13. Camilleri, J. Hydration mechanisms of mineral trioxide aggregate. Int. Endod. J. 2007, 40, 462-470. [CrossRef]

14. Hiremath, G.S.; Kulkarni, R.D.; Naik, B.D. Evaluation of minimal inhibitory concentration of two new materials using tube dilution method: An in vitro study. J. Conserv. Dent. JCD 2015, 18, 159-162. [CrossRef]

15. Kangarlou, A.; Sofiabadi, S.; Yadegari, Z.; Asgary, S. Antifungal effect of calcium enriched mixture cement against Candida albicans. Iran. Endod. J. 2009, 4, 101-105. [PubMed]

16. Kangarlou, A.; Sofiabadi, S.; Asgary, S.; Mahjour, F.; Dianat, O.; Yadegari, Z.; Younessian, F. Assessment of antifungal activity of ProRoot mineral trioxide aggregate and mineral trioxide aggregate-Angelus. Dent. Res. J. 2012, 9, 256-260. 
17. Ramage, G.; Walle, K.V.; Wickes, B.L.; López-Ribot, J.L. Standardized method for in vitro antifungal susceptibility testing of Candida albicansbiofilms. Antimicrob. Agents Chemother. 2001, 45, 2475-2479. [CrossRef]

18. Ceri, H.; Olson, M.; Stremick, C.; Read, R.; Morck, D.; Buret, A. The Calgary Biofilm Device: New technology for rapid determination of antibiotic susceptibilities of bacterial biofilms. J. Clin. Microbiol. 1999, 37, 1771-1776. [CrossRef]

19. Lovato, K.F.; Sedgley, C.M. Antibacterial activity of endosequence root repair material and proroot MTA against clinical isolates of Enterococcus faecalis. J. Endod. 2011, 37, 1542-1546. [CrossRef]

20. Damlar, I.; Ozcan, E.; Erkan, Y.; Yalcin, M.; Celik, S. Antimicrobial effects of several calcium silicate-based root-end filling materials. Dent. Mater. J. 2014, 33, 453-457. [CrossRef] [PubMed]

21. Kim, R.J.-Y.; Kim, M.-O.; Lee, K.-S.; Lee, D.-Y.; Shin, J.-H. An in vitro evaluation of the antibacterial properties of three mineral trioxide aggregate (MTA) against five oral bacteria. Arch. Oral Biol. 2015, 60, 1497-1502. [CrossRef]

22. Donyavi, Z.; Heidari, N.; Khoshbin, E.; Shahriari, S.; Farhadian, M.; Mashouf, R.Y.; Esmaeilzadeh, M. Antibacterial activity of mineral trioxide aggregate, new endodontic cement, Retro MTA and Ortho MTA against common endodontic pathogens. Indo Am. J. Pharm. Sci. 2017, 4, 4720-4728.

23. Atom, J.; Devi, N.R.; Lairenlakpam, R.; Al Wadei, M.H.D.; Hakami, A.R.; BinShaya, A.S. Antimicrobial efficacy of different pulp-capping materials against Enterococcus faecalis: An In vitro study. J. Pharm. Bioallied Sci. 2021, 13, 608-611. [CrossRef]

24. Bossù, M.; Mancini, P.; Bruni, E.; Uccelletti, D.; Preziosi, A.; Rulli, M.; Relucenti, M.; Donfrancesco, O.; Iaculli, F.; Di Giorgio, G. Biocompatibility and Antibiofilm Properties of Calcium Silicate-Based Cements: An In Vitro Evaluation and Report of Two Clinical Cases. Biology 2021, 10, 470. [CrossRef]

25. Jardine, A.P.; Montagner, F.; Quintana, R.M.; Zaccara, I.M.; Kopper, P.M.P. Antimicrobial effect of bioceramic cements on multispecies microcosm biofilm: A confocal laser microscopy study. Clin. Oral Investig. 2019, 23, 1367-1372. [CrossRef] [PubMed]

26. Austin, P.; Brine, C.; Castle, J.; Zikakis, J. Chitin: New facets of research. Science 1981, 212, 749-753. [CrossRef]

27. Matica, M.A.; Aachmann, F.L.; Tøndervik, A.; Sletta, H.; Ostafe, V. Chitosan as a Wound Dressing Starting Material: Antimicrobial Properties and Mode of Action. Int. J. Mol. Sci. 2019, 20, 5889. [CrossRef] [PubMed]

28. Goy, R.C.; Morais, S.T.; Assis, O.B. Evaluation of the antimicrobial activity of chitosan and its quaternized derivative on E. coli and S. aureus growth. Rev. Bras. De Farmacogn. 2016, 26, 122-127. [CrossRef]

29. del Carpio-Perochena, A.; Kishen, A.; Shrestha, A.; Bramante, C.M. Antibacterial properties associated with chitosan nanoparticle treatment on root dentin and 2 types of endodontic sealers. J. Endod. 2015, 41, 1353-1358. [CrossRef]

30. Yadav, P.; Chaudhary, S.; Saxena, R.K.; Talwar, S.; Yadav, S. Evaluation of Antimicrobial and Antifungal efficacy of Chitosan as endodontic irrigant against Enterococcus Faecalis and Candida Albicans Biofilm formed on tooth substrate. J. Clin. Exp. Dent. 2017, 9, e361-e367. [CrossRef] [PubMed]

31. Park, Y.; Kim, M.-H.; Park, S.-C.; Cheong, H.; Jang, M.-K.; Nah, J.-W.; Hahm, K.-S. Investigation of the antifungal activity and mechanism of action of LMWS-chitosan. J. Microbiol. Biotechnol. 2008, 18, 1729-1734.

32. Beck, B.H.; Yildirim-Aksoy, M.; Shoemaker, C.A.; Fuller, S.A.; Peatman, E. Antimicrobial activity of the biopolymer chitosan against Streptococcus iniae. J. Fish. Dis. 2019, 42, 371-377. [CrossRef]

33. del Carpio-Perochena, A.; Kishen, A.; Felitti, R.; Bhagirath, A.Y.; Medapati, M.R.; Lai, C.; Cunha, R.S. Antibacterial properties of chitosan nanoparticles and propolis associated with calcium hydroxide against single-and multispecies biofilms: An in vitro and in situ study. J. Endod. 2017, 43, 1332-1336. [CrossRef] [PubMed]

34. Beshr, K.A.; Abdelrahim, R.A. Antibacterial efficacy of Allium sativum (garlic) and chitosan incorporated into two root canal sealers against Enterococcus faecalis: Comparative study. Tanta Dent. J. 2019, 16, 94-98.

35. del Carpio-Perochena, A.; Bramante, C.M.; Duarte, M.A.H.; de Moura, M.R.; Aouada, F.A.; Kishen, A. Chelating and antibacterial properties of chitosan nanoparticles on dentin. Restor. Dent. Endod. 2015, 40, 195-201. [CrossRef]

36. Abusrewil, S.; Brown, J.L.; Delaney, C.D.; Butcher, M.C.; Kean, R.; Gamal, D.; Scott, J.A.; McLean, W.; Ramage, G. Filling the Void: An Optimized Polymicrobial Interkingdom Biofilm Model for Assessing Novel Antimicrobial Agents in Endodontic Infection. Microorganisms 2020, 8, 1988. [CrossRef]

37. Raghavendra, S.S.; Jadhav, G.R.; Gathani, K.M.; Kotadia, P. Bioceramics in endodontics-A review. J. Istanb. Univ. Fac. Dent. 2017, 51, 128-137. [CrossRef] [PubMed]

38. Shin, J.M.; Luo, T.; Lee, K.H.; Guerreiro, D.; Botero, T.M.; McDonald, N.J.; Rickard, A.H. Deciphering endodontic microbial communities by next-generation sequencing. J. Endod. 2018, 44, 1080-1087. [CrossRef]

39. Mergoni, G.; Percudani, D.; Lodi, G.; Bertani, P.; Manfredi, M. Prevalence of Candida Species in Endodontic Infections: Systematic Review and Meta-analysis. J. Endod. 2018, 44, 1616-1625. [CrossRef]

40. Zehnder, M.; Waltimo, T.; Sener, B.; Söderling, E. Dentin enhances the effectiveness of bioactive glass S53P4 against a strain of Enterococcus faecalis. Oral Surg. Oral Med. Oral Pathol. Oral Radiol. Endodontol. 2006, 101, 530-535. [CrossRef] [PubMed]

41. Zhang, H.; Pappen, F.G.; Haapasalo, M. Dentin enhances the antibacterial effect of mineral trioxide aggregate and bioaggregate. J. Endod. 2009, 35, 221-224. [CrossRef]

42. Smith, J.; Smith, A.; Shelton, R.; Cooper, P. Antibacterial activity of dentine and pulp extracellular matrix extracts. Int. Endod. J. 2012, 45, 749-755. [CrossRef]

43. Arana-Chavez, V.E.; Massa, L.F. Odontoblasts: The cells forming and maintaining dentine. Int. J. Biochem. Cell Biol. 2004, 36, 1367-1373. [CrossRef] [PubMed] 
44. Miller, J.H.; Avilés-Reyes, A.; Scott-Anne, K.; Gregoire, S.; Watson, G.E.; Sampson, E.; Progulske-Fox, A.; Koo, H.; Bowen, W.H.; Lemos, J.A. The collagen binding protein Cnm contributes to oral colonization and cariogenicity of Streptococcus mutans OMZ175. Infect. Immun. 2015, 83, 2001-2010. [CrossRef]

45. Love, R.; Jenkinson, H. Invasion of dentinal tubules by oral bacteria. Crit. Rev. Oral Biol. Med. 2002, 13, 171-183. [CrossRef] [PubMed]

46. Swimberghe, R.; Coenye, T.; De Moor, R.; Meire, M. Biofilm model systems for root canal disinfection: A literature review. Int. Endod. J. 2019, 52, 604-628. [CrossRef]

47. Chivatxaranukul, P.; Dashper, S.; Messer, H. Dentinal tubule invasion and adherence by Enterococcus faecalis. Int. Endod. J. 2008, 41, 873-882. [CrossRef]

48. Bachmann, L.; Gomes, A.S.; Zezell, D.M. Collagen absorption bands in heated and rehydrated dentine. Spectrochim. Acta Part. A Mol. Biomol. Spectrosc. 2005, 62, 1045-1049. [CrossRef]

49. Roberts, A.E.; Kragh, K.N.; Bjarnsholt, T.; Diggle, S.P. The limitations of in vitro experimentation in understanding biofilms and chronic infection. J. Mol. Biol. 2015, 427, 3646-3661. [CrossRef] [PubMed]

50. Thein, Z.M.; Samaranayake, Y.H.; Samaranayake, L.P. Effect of oral bacteria on growth and survival of Candida albicans biofilms. Arch. Oral Biol. 2006, 51, 672-680. [CrossRef]

51. Bor, B.; Cen, L.; Agnello, M.; Shi, W.; He, X. Morphological and physiological changes induced by contact-dependent interaction between Candida albicans and Fusobacterium nucleatum. Sci. Rep. 2016, 6, 27956. [CrossRef] [PubMed]

52. Kean, R.; Rajendran, R.; Haggarty, J.; Townsend, E.M.; Short, B.; Burgess, K.E.; Lang, S.; Millington, O.; Mackay, W.G.; Williams, C. Candida albicans mycofilms support Staphylococcus aureus colonization and enhances miconazole resistance in dual-species interactions. Front. Microbiol. 2017, 8, 258. [CrossRef]

53. Graham, C.E.; Cruz, M.R.; Garsin, D.A.; Lorenz, M.C. Enterococcus faecalis bacteriocin EntV inhibits hyphal morphogenesis, biofilm formation, and virulence of Candida albicans. Proc. Natl. Acad. Sci. USA 2017, 114, 4507-4512. [CrossRef]

54. Krishnamoorthy, A.L.; Lemus, A.A.; Solomon, A.P.; Valm, A.M.; Neelakantan, P. Interactions between Candida albicans and Enterococcus faecalis in an Organotypic Oral Epithelial Model. Microorganisms 2020, 8, 1771. [CrossRef]

55. Young, T.; Alshanta, O.-A.; Kean, R.; Bradshaw, D.; Pratten, J.; Williams, C.; Woodall, C.; Ramage, G.; Brown, J.L. Candida albicans as an essential "keystone" component within polymicrobial oral biofilm models? Microorganisms 2021, 9, 59. [CrossRef]

56. Harriott, M.M.; Noverr, M.C. Candida albicans and Staphylococcus aureus form polymicrobial biofilms: Effects on antimicrobial resistance. Antimicrob. Agents Chemother. 2009, 53, 3914-3922. [CrossRef] [PubMed]

57. Al-Hezaimi, K.; Al-Shalan, T.A.; Naghshbandi, J.; Oglesby, S.; Simon, J.H.; Rotstein, I. Antibacterial effect of two mineral trioxide aggregate (MTA) preparations against Enterococcus faecalis and Streptococcus sanguis in vitro. J. Endod. 2006, 32, 1053-1056. [CrossRef] [PubMed]

58. Abou ElReash, A.; Hamama, H.; Eldars, W.; Lingwei, G.; El-Din, A.M.Z.; Xiaoli, X. Antimicrobial activity and pH measurement of calcium silicate cements versus new bioactive resin composite restorative material. BMC Oral Health 2019, 19, 235. [CrossRef]

59. Tsai, G.-J.; Su, W.-H. Antibacterial activity of shrimp chitosan against Escherichia coli. J. Food Prot. 1999, 62, 239-243. [CrossRef] [PubMed]

60. Aleanizy, F.S.; Alqahtani, F.Y.; Shazly, G.; Alfaraj, R.; Alsarra, I.; Alshamsan, A.; Abdulhady, H.G. Measurement and evaluation of the effects of $\mathrm{pH}$ gradients on the antimicrobial and antivirulence activities of chitosan nanoparticles in Pseudomonas aeruginosa. Saudi Pharm. J. 2018, 26, 79-83. [CrossRef]

61. Kong, M.; Chen, X.-g.; Xue, Y.-p.; Liu, C.-s.; Yu, L.-j.; Ji, Q.-x.; Cha, D.S.; Park, H.J. Preparation and antibacterial activity of chitosan microshperes in a solid dispersing system. Front. Mater. Sci. China 2008, 2, 214-220. [CrossRef]

62. Wani, T.U.; Pandith, A.H.; Sheikh, F.A. Polyelectrolytic nature of chitosan: Influence on physicochemical properties and synthesis of nanoparticles. J. Drug Deliv. Sci. Technol. 2021, 65, 102730. [CrossRef]

63. de Dios Teruel, J.; Alcolea, A.; Hernández, A.; Ruiz, A.J.O. Comparison of chemical composition of enamel and dentine in human, bovine, porcine and ovine teeth. Arch. Oral Biol. 2015, 60, 768-775. [CrossRef]

64. Sherry, L.; Lappin, G.; O’Donnell, L.E.; Millhouse, E.; Millington, O.R.; Bradshaw, D.J.; Axe, A.S.; Williams, C.; Nile, C.J.; Ramage, G. Viable compositional analysis of an eleven species oral polymicrobial biofilm. Front. Microbiol. 2016, 7, 912.

65. Kean, R.; Delaney, C.; Sherry, L.; Borman, A.; Johnson, E.M.; Richardson, M.D.; Rautemaa-Richardson, R.; Williams, C.; Ramage, G. Transcriptome Assembly and Profiling of Candida auris Reveals Novel Insights into Biofilm-Mediated Resistance. Msphere 2018, 3, e00334-18. [CrossRef] [PubMed] 